\section{EMBRYRIDDLE \\ Aeronautical University}

SCHOLARLY COMMONS
International Journal of Aviation, Aeronautics, and Aerospace

\title{
Attitudes Toward Controlled Rest in Position (CRIP): A Gender Comparison Between Pilots and Non-Pilots
}

\author{
Stephen Rice \\ Embry-Riddle Aeronautical University, rices15@erau.edu \\ Scott R. Winter \\ Embry-Riddle Aeronautical University, scott.winter@mac.com \\ Gajapriya Tamilselvan \\ Florida Institute of Technology - Melbourne, gtamilselvan2014@my.fit.edu \\ Mattie N. Milner \\ Embry-Riddle Aeronautical University, milnerm1@my.erau.edu
}

Follow this and additional works at: https://commons.erau.edu/ijaaa

Part of the Other Psychology Commons

\section{Scholarly Commons Citation}

Rice, S., Winter, S. R., Tamilselvan, G., \& Milner, M. N. (2017). Attitudes Toward Controlled Rest in Position (CRIP): A Gender Comparison Between Pilots and Non-Pilots. International Journal of Aviation, Aeronautics, and Aerospace, 4(3). https://doi.org/10.15394/ijaaa.2017.1181

This Article is brought to you for free and open access by the Journals at Scholarly Commons. It has been accepted for inclusion in International Journal of Aviation, Aeronautics, and Aerospace by an authorized administrator of Scholarly Commons. For more information, please contact commons@erau.edu. 
In commercial aviation, in-flight pilot fatigue serves as a persistent threat to flight safety and potential mitigation factors are fiercely debated. Controlled rest in position (CRIP) is possibly the most practical countermeasure to combat in-flight fatigue (Hartzler, 2013) and is employed by several aviation companies around the world (Werfelman, Rash, \& Manning, 2009). Although CRIP is not in practice in the United States, this study attempts to compare attitudes of consumers and pilots toward the use of CRIP, for determining their willingness to fly as passengers on a commercial flight. While CRIP provides a strong countermeasure for helping combat pilot fatigue, it has been received with varying levels of acceptance in the aviation community. It is vital that any newly introduced policy at an airline needs to be accepted by the traveling public and the pilots if the program is to succeed and provide maximum benefits. The study attempts to determine consumer 'buyin' to help reduce government and airline uncertainty on adopting CRIP in their operations. Determining consumer acceptance could lead to the development of a unified standard for practicing CRIP and combating pilot fatigue in flight.

\section{Literature Review}

\section{Pilot Fatigue}

Pilot fatigue is one of the biggest threats to aviation safety due to circadian rhythm disturbances and other homeostatic factors (Hartzler, 2013). Hartzler (2013) discussed the negative consequences associated with pilots' extended duty periods and how neurocognitive performance may decline during long international flights. Pilots suffering from sleep deprivation are a common problem related to long flights due to pilots engaging in abnormally early or late duty periods. Pilots have rapidly changing schedules, which may vary from day-to-day, week-to-week, and even month-to-month; therefore, it is difficult for them to maintain their natural circadian rhythm. Rapidly switching between different schedules often results in dangerous levels of fatigue (Powell, Spencer, Holland, Broadbent, \& Petrie, 2007).

There have been some recent regulatory changes to address pilot fatigue. 14 CFR Part 117 went into effect on January 4, 2014. These new regulations are based on scientific findings and create new flight duty periods/limitations for crews and the incorporation of tools such as fatigue risk management systems (ALPA, 2013). While 14 CFR Part 117 is the first major update to flight duty rules in 60 years, there are still some exceptions, for example, cargo pilots are not included in the new regulations (ALPA, 2013).

Sleep deprivation is a common problem, which leads to impairment of neurobehavioral functioning. If a person is suffering from sleep deprivation, their 
performance will start degrading over a period; therefore, it is important to investigate performance across multiple sleep wake cycles (Dorrian, Rogers, Dinges, 2005). A study on sleep deprivation and neurocognitive performance utilized the psychomotor vigilance task (PVT) to determine the impact of response blocks and lapse hypothesis on neurocognitive performance (Dorrian et al., 2005). Response blocks represent the time it takes a person to pause between two distinct tasks, and this amount of time is equivalent to the time of two or more average responses. Lapse hypotheses provide a theoretical foundation to investigate the effects of sleep loss on cognitive performance.

A study regarding commercial pilot schedules over the past 20 years discovered that there is a positive correlation between a number of time pilots are on duty and the probability of an accident (Goode, 2003). Because pilots can be on duty for extended periods of time, technology attempts to help by reducing the pilots' workload through automation of the cockpit and navigational tools. However, an automated cockpit forces the pilot into the role of a passive monitor and that combined with environmental factors such as dim cockpit lighting and reduced blood oxygenation, from operating at high altitudes, contributes to overall fatigue (Hartzler, 2013).

Factors such as circadian rhythm disturbances, sleep deprivation, and cockpit automation all contribute to pilot fatigue, which may manifest itself via inflight micro-sleeps Caldwell, 2005). Pilot micro-sleeps occur most often during the cruise portion of a long flight. Furthermore, pilots are nine times more likely to engage in micro-sleeps during nighttime flights compared to daytime flights (Caldwell, 2005). Interestingly, the pilots seemed to be unaware that they had been dozing off (Caldwell, 2005). Roach et al. (2011) conducted a study investigating the effects of fatigue on the amount of planned in-flight sleep obtained by airline pilots in crew rest quarters during long-haul duty periods. The results indicate that long haul pilots have a higher likelihood of sleeping more when their fatigue is rated as extreme; therefore, in-flight napping (perhaps such as CRIP) could be used as a fatigue countermeasure.

\section{Empirical Research on CRIP}

A recurring theme throughout in-flight napping literature reveals that allowing pilots to have frequent, short naps improve situational awareness, which in turn promotes safety. Performance deficits due to sleep loss or sleep disruption could potentially be reversed with strategic napping. Pilots napping for as little as ten minutes could help reduce sleepiness and improve neurophysical performance (Hatzler, 2013). Currently, pilots napping while on duty is not allowed under the 
regulations of the Federal Aviation Administration (FAA), but a few foreign airlines allow napping as an effective fatigue mitigation tool. A NASA Ames study (1994) discovered that participants who slept forty minutes showed superior ratings in objective measures such as response times and subjective alertness when compared to the control group, which received no rest. An additional study posited that performance and physiological alertness could be improved by napping for a period of 2-12 hours (Rosekind et al., 1995). The Air Canada Flight Operations Manual (FOM) addresses controlled rest parameters as follows:

Section 2.9.10 - Alertness Management, describes controlled rest as an operational fatigue countermeasure that improves on-the-job performance and alertness when compared to non-countermeasure conditions. Controlled rest uses strategic napping on the flight deck to improve crew alertness during critical phases of flight. The rest periods are a maximum of 40 minutes in length (periods to be reviewed prior to resting) and must be completed 30 minutes prior to the top of descent. The In-Charge Flight Attendant must be advised that controlled rest will be taking place and instructed to call the flight deck at a specific time. Upon conclusion of the rest period, unless required due to an abnormal or emergency situation, the awakened pilot should be provided at least 15 minutes without any flight duties to become fully awake before resuming normal duties. An operational briefing shall follow (TSB, 2011, p. 2).

The Federal Aviation Administration's (FAA) reluctance to introduce CRIP as part of their procedures may be due to side effects like sleep inertia.

Sleep inertia has been defined as, "...the period of cognitive and mood impairment, as well as hypo-vigilance, experienced immediately upon awakening..." (Hartzler, 2013, p. 314). Additionally, Ferrara and De Gennaro (2000) state sleep inertia can cause undesirable effects approximately 30-60 minutes after waking up, and those effects can last up to two hours after awakening. These negative side effects may include confusion, disorientation, and poor dexterity. Simple industry procedures to mitigate sleep inertia include limiting rest periods to cruise flight and requiring pilots to be awake for a stipulated period of time before commencing normal duties.

A study on workplace evaluation at an aircraft maintenance facility had workers engage in strategic napping during 12-hour overnight shifts and determined the effects on performance, alertness, and subsequent sleep (Purnell et al., 2002). Workers experienced improvements in response time when allowed to 
take a short 20-minute nap. Driskell and Mullen (2005) conducted a meta-analysis summarizing the effects of naps as a fatigue countermeasure and determined the impact naps have on performance and feelings of fatigue. The meta-analysis recommended developing optimal work schedules to diminish fatigue and increase safety.

\section{Affective Theoretical Foundation}

Consumer behavior is influenced by a multitude of factors, such as consumer willingness, internal biases, opinions, and affect (or emotions). Consumer-based research has focused on the role of emotional influence (affect) on decision-making processes (Bodenhausen, 1993; Bower, 1991; Clore, Schwarz, \& Conway, 1994; Forgas, 1995; Loewenstein, 1996; Schwarz \& Clore, 1996; Zajonc, 1998). Emotions are necessary for quickly processing information, and humans can make deliberate decisions only after processing information for a significant amount of time (Frijda, 1986; Levenson, 1994; Oatley \& Johnson-Laird, 1996).

Lazarus (1991) proposed a cognitive-motivational-relational theory to describe the capabilities of emotions and to predict them. The main tasks of a theory of emotion were explored, with the first part being able to offer general propositions about the emotional process and the second part explains about the specific propositions about each of the individual emotions. The general propositions about the emotional process include setting up the variables and ways in which emotions are operationally defined. Individual emotions correspond to anger, anxiety, sadness, pride, and their propositions need to explain subsequent actions and reactions.

Lazarus (1991) named this theory as relational, motivational, and cognitive. The term 'relational' explains about the role of emotions in person-environment relationships, involving both harms and benefits. Usually, harms are outcomes of negative emotions and benefits are from positive emotions. Lazarus (1991) stated in his central premise that, "each emotion involves a distinctive core relational theme, which is a molar way of describing the essence of the person-environment relationship for that emotion" (p. 820).

The term 'motivational' was given to this theory to understand how motivation is related to acute emotions and moods. The term 'cognitive' describes personal knowledge, which consists of situational and generalized beliefs to tackle any encounter with the environment. Lazarus (1991) classified emotions in four categories. First, negative emotions are those emotions resulting from harms, losses, and threats and include emotions such as anger, anxiety, fear, guilt, shame, 
sadness, envy, jealousy, and disgust. Second, positive emotions are those resulting from benefits, and these include emotions such as happiness, joy, pride, gratitude, and love. The third category is borderline cases includes hope, contentment, relief, compassion, and aesthetic emotions. Finally, nonemotions are comprised of outcomes from several subcategories like complex states (grief and depression), ambiguous positive states (expansiveness, challenge, confidence, determination), ambiguous negative states (frustration, disappointment, meaninglessness), mental confusion (bewilderment, confusion), content less excitement or arousal (upset, distress, nervousness, tension, agitation) and pre-emotions (interest, curiosity, anticipation, alertness, surprise, amazement). Furthermore, the cognitivemotivational-relational theory of emotion assists us to understand the generation of emotions and their subsequent adaptations. This theory imparts knowledge to relate any pattern of emotion back to its causation.

\section{Affective Theory in Aviation}

Using affect as a mediator is a common theme throughout research aviation because flying tends to invoke strong emotions in consumers and pilots. A study involving unmanned aerial vehicles (UAVs) evaluated participants' reactions to two UAV missions that potentially raised privacy concerns (Winter, Rice, Tamilselvan, \& Tokarski, 2016). The participants' concerns for privacy were captured by affective measures, where two (disgust and fear) of six unique and universal facial expressions mediated the relationship between the type of UAV missions and privacy concerns.

Rice, Winter, and Tokarski (2015) conducted a study examining the relationship between pilot's perceived sociability and consumer trust ratings in their pilot using participants from India and the United States. The above study incorporated affect as the mediator variable, which mediated the relationship between sociable/unsociable conditions and consumer trust ratings on their pilot. Winter and Rice (2015) studied public perceptions of pilot behaviors and perceived mental illness using affective theory. They found that affect acts as a mediator between sociability of the pilot and perceived likelihood of mental illness among participants from India and the United States.

\section{General Willingness and Consumer Acceptance}

The study is mainly focused on investigating consumer perceptions regarding the level of consumer willingness to fly in CRIP protocols. Willingness, as defined by thefreedictionary (2014) is "done, given, accepted, or borne voluntarily or ungrudgingly" (n.p.). A few major features affecting consumer perceptions include personality characteristics, service and technology 
characteristics, and situational factors (Pramatari \& Theotokis, 2009). Unfortunately, airlines cannot guarantee that all their consumers will view the company with positive perceptions, and it is infeasible to change the mind of every consumer to favor CRIP. The work by Zhao and Kling (2004) conveys details to the regulators and top airline management. According to Zhao and Kling (2004):

How much one is willing to pay (or accept) for a good at a particular point in time will depend on... the ability to reduce the risk of a bad purchase or sale by gathering more information, and the ease of later reversing the transaction. (p. 504)

Key factors influencing customer willingness are issues associated with perceived risk and product involvement (Dholakia, 2001). Risk perceptions are accompanied by any product, and they are cognitively evaluated by the consumer. This risk perception may be different with airlines and regulators; travelers are distinct, regarding their personalized thought processes. Also, the amount of time, money, and research the consumer has invested in the product (known as product involvement), may influence the perceived risk a consumer may feel (Dholakia, 2001). Therefore if a consumer has invested a lot in any one of these three factors, before purchasing a product, they may perceive their risk as smaller.

A leading model in the field of consumer acceptance has been the Technology Acceptance Model (TAM), which was created by Davis (1989). TAM was formed to understand how humans accepted and used new technology. Two of the key concepts related to TAM is on the perceived usefulness and the perceived ease of use. The greater the perceived usefulness and the greater the perceived ease of use, the more likely consumers will accept the technology Follow-on research was later completed by Adams, Nelson, and Todd (1992) which replicated the findings from Davis (1989). While CRIP may not be directly related to technology, tenants from the technology acceptance model may influence perceptions toward CRIP. For example, if passengers view a benefit from CRIP, they may be more likely to accept its use and indicate a willingness to fly.

The proposed study focuses specifically on evaluating a consumer's willingness to fly if the pilot is using CRIP. A reduction in airline passenger traffic is expected if the passengers have negative opinions regarding CRIP procedures, which will be a concern for airline management. The study may impart valuable information on consumer perceptions toward the use of CRIP procedures.

\section{Willingness to Fly Empirical Research}


The study uses a previously validated scale to measure consumer willingness to fly (Rice et al., 2015). The willingness to fly scale was created with different stages, including word generation, word pairing, validation, discrimination, and scenario-based applications; and consumers were present in all stages of the scale development. The final instrument constitutes seven statements measuring a consumer's willingness to fly using a 5-point scale from Strongly Disagree to Strongly Agree. A copy of the instrument can be found in Appendix B.

Rice and Winter (2015) conducted a study examining the relationship between pilot configuration and willingness to fly and how the relationship was mediated by six specific emotions. Out of the six universal emotions, three emotions significantly mediated the relationship between pilot configuration and willingness to fly: anger, fear, and happiness, respectively. In another empirical study on willingness to fly, Winter, Rice, Rains, Milner, and Mehta (2017) administered a longitudinal study on consumers' willingness to fly when their pilots are taking four antidepressants (fluoxetine, loratadine, ibuprofen or clonidine) and the study was conducted in the weeks following 2015 Germanwings accident. The results of the study revealed a reduction in willingness to fly scores for the fluoxetine condition immediately after the accident; nevertheless, other medications did not have any significant change on a willingness to fly scores (Winter, Rice, Rains, Milner, \& Mehta, 2017).

\section{CRIP Consumer Perception Studies}

In 2015, a study was conducted determining overall consumer willingness to fly while the pilot is using CRIP procedures in the United States (Winter, Carryl, $\&$ Rice, 2015). The study examined the effect of participants' gender on consumer's willingness to fly and the mediating factor on the relationship between pilots' use of CRIP and consumers' willingness to fly using affect measures. Low willingness to fly scores were associated with both male and female participants when CRIP procedures were used. Additionally, affect acted as mediator variable between the use of CRIP and consumers' willingness to fly.

\section{Current Study}

A review of the literature shows that while CRIP has been discussed in the aviation literature, there are some missing gaps that have not been thoroughly researched such as current commercial airline pilot's views toward CRIP. This study sought to fill one of these missing gaps by tapping into consumer attitudes 
towards CRIP in the United States. In the first study, the participants were nonpilots. In hypothetical scenarios, we manipulated the length of the flight as well as the number of passengers on board. Our third non-manipulated variable was gender. The four hypotheses were as follows:

H1a: Willingness to fly ratings would be lower for shorter flights.

H2a: Willingness to fly ratings would be affected by the number of passengers; that is, a CRIP flight with more passengers would generate lower willingness to fly scores.

H3a: Willingness to fly scores would differ as a function of gender. This was a non-directional hypothesis.

H4a: Affect would mediate the relationship between the IVs and willingness to fly.

\section{Methods}

\section{Study 1}

Participants. There were 201 participants (96 females) in this study. The mean age was 35.21 years $(\mathrm{SD}=11.82)$. All participants were recruited from the United States via a convenience sample using Amazon's ${ }^{\circledR}$ Mechanical Turk ${ }^{\circledR}$ (MTurk). MTurk provides a pool of over 500,000 worldwide participants who complete human intelligence tasks in exchange for monetary compensation. Prior research has shown that data from MTurk is as reliable as standard laboratory data (Buhrmester, Kwang, \& Gosling, 2011; Germine et al., 2012).

Materials and Procedure. Participants were given an electronic consent form to sign, after which they read instructions about the study. Participants were then presented with information about CRIP. Specifically, participants were told: "Controlled Rest in Position (CRIP) allows pilots to nap while remaining in the cockpit seat during the non-critical stages of flight. Take-off, climb, approach, and landing is considered the critical phases of flight, whereas when the aircraft is at cruise altitude, it is considered noncritical. Controlled rest in position (CRIP) has been suggested as a viable countermeasure to the Federal Aviation Administration (FAA) in the ongoing efforts to combat in-flight pilot fatigue. It is already in use in other parts of the world; however, it is not currently permitted in the United States. In some countries where CRIP is used, they have a strict policy on how it is implemented. For example, when the pilot wants to take a nap, s/he has to inform the co-pilot and flight attendants. When the pilot wakes, s/he cannot perform any essential tasks until s/he is fully awake (e.g. 20 minutes). However, this does not 
apply to emergency situations, where the pilot might be expected to operate the aircraft immediately."

Following this, participants were presented with the following hypothetical scenario: "Imagine that you are a passenger on a 2-hour flight from one city to another. There are 50 passengers on board. You are told that the pilots on board will be allowed to use CRIP during this flight. Controlled Rest in Position (CRIP) allows pilots to nap while remaining in the cockpit seat during the non-critical stages of flight." Participants were then asked to fill out the Affect Scale (see Appendix A), followed by the Willingness to Fly Scale (see Appendix B). In another condition, the length of the flight was changed to 14 hours. In a third condition and fourth condition, the first two conditions were crossed with a flight with 50 passengers and a flight with 300 passengers, respectively. Thus, there were four conditions with two factors: Condition 1 was a 2-hour flight with 50 passengers. Condition 2 was a 14-hour flight with 50 passengers. Condition 3 was a 2-hour flight with 300 passengers. Condition 4 was a 14-hour flight with 300 passengers. The order of the conditions was randomized.

Design. All participants were presented with all four conditions. Gender was a between-participants factor. Thus, we used a mixed three-way factorial design. Table 1 depicts the design along with average willingness to fly scores, standard deviations, and sample size.

\section{Results}

\section{Study 1}

The study used two valid instruments. The first instrument was an Affect scale (Rice \& Winter, 2015). To verify internal consistency, a Cronbach's Alpha test was completed on this data and values ranged from .974 to .978, which implies high internal consistency. This allowed the data to be averaged into one affect score per participant. The second instrument was a valid measure of consumer willingness to fly (Rice et al., 2015). A Cronbach's Alpha revealed values ranging from .977 to .982 , thus indicating high internal consistency. Therefore, the scores were averaged into one willingness to fly score per participant. 
Table 1

A 2x2x2 three-way mixed factorial design was used for Study 1 with the length of flight and number of passengers as within factors and gender as a between factor. Average willingness to fly scores, standard deviations and number of participants are depicted.

\begin{tabular}{lllll}
\hline Conditions & Gender & $\begin{array}{l}\text { Avg. Willingness to } \\
\text { Fly Score }\end{array}$ & $\begin{array}{l}\text { Standard } \\
\text { Deviation }\end{array}$ & $\mathrm{N}$ \\
\hline \multirow{3}{*}{ 2 hour, 50 Passengers } & Male & -0.23 & 1.15 & 105 \\
& Female & -0.72 & 1.12 & 96 \\
& Total & -0.47 & 1.16 & 201 \\
& Male & -0.28 & 1.18 & 105 \\
2 hour, 300 passengers & Female & -0.85 & 1.15 & 96 \\
& Total & -0.55 & 1.20 & 201 \\
& Male & 0.16 & 1.14 & 105 \\
14 hour, 50 passengers & Female & -0.24 & 1.27 & 96 \\
& Total & -0.03 & 1.22 & 201 \\
& Male & 0.17 & 1.17 & 105 \\
14 hour, 300 passengers & Female & -0.24 & 1.27 & 96 \\
& Total & -0.03 & 1.23 & 201 \\
\hline
\end{tabular}

Inferential Statistics. A mixed $2 \times 2 \times 2$ factorial ANOVA analysis was conducted on the data using length of flight and number of passengers as within participant factors and gender as the between participants factor. For the affect data, the main effect of length of flight was found to be significant, $F(1,199)=68.62, p$ $<0.001, \eta p^{2}=0.256$, and there was a significant main effect of gender, $F(1,199)=$ 6.24, $p<0.05, \eta p^{2}=0.030$. There was no significant main effect of number of passengers, $F(1,199)=3.35, p=0.07, \eta p^{2}=0.017$. There was not a significant interaction between length of flight and gender, $F(1,199)=0.182, p=0.670, \eta p^{2}=$ 0.001 , between number of passengers and gender, $F(1,199)=0.98, p=0.323, \eta p^{2}$ $=0.005$, nor between length of flight, number of passengers, and gender, $F(1,199)$ $=1.741, p=0.188, \eta p^{2}=0.009$. There was a significant interaction between length of flight and number of passengers, $F(1,199)=8.38, p<0.01, \eta p^{2}=0.040$. Study results are depicted in Figure 1. For the willingness to fly data, the main effect of length of flight was found to be significant, $F(1,199)=68.46, p<0.001, \eta p^{2}=$ 0.256 , as well as that of number of passengers, $F(1,199)=5.08, p<0.05, \eta p^{2}=$ 0.025 , and gender, $F(1,199)=9.01, p<0.01, \eta p^{2}=0.043$. There was also a significant interaction between length of flight and number of passengers, $F(1,199)$ $=9.86, p<0.01, \eta p^{2}=0.047$. There was no significant interaction between length of flight and gender, $F(1,199)=1.24, p=0.268, \eta p^{2}=0.006$, number of passengers 
and gender, $F(1,199)=1.90, p=0.170, \eta p^{2}=0.009$, nor length of flight, number of passengers, and gender, $F(1,199)=1.42, p=0.235, \eta p^{2}=0.007$. Willingness to fly data are depicted in Figure 2.

Mediation Analyses. For the 2-hour, 50-passenger condition: The standardized regression coefficient between gender and affect was statistically significant, as was the relationship between affect and willingness to fly. The significance of this indirect effect was tested using bootstrapping procedures (Hayes, 2013) with 1,000 bootstrapped samples. The bootstrapped 95\% confidence interval ranged from -0.5408 to -0.0006 . Thus, the indirect effect was statistically significant, and there was mediation.

For the 2-hour, 300-passenger condition: The standardized regression coefficient between gender and affect was statistically significant, as was the relationship between affect and willingness to fly. The significance of this indirect effect was tested using bootstrapping procedures (Hayes, 2013) with 1,000 bootstrapped samples. The bootstrapped $95 \%$ confidence interval ranged from 0.6863 to -0.1167 . Thus, the indirect effect was statistically significant, and there was mediation.

For the 14-hour, 50-passenger condition: The standardized regression coefficient between gender and affect was statistically significant, as was the relationship between affect and willingness to fly. The significance of this indirect effect was tested using bootstrapping procedures (Hayes, 2013) with 1,000 bootstrapped samples. The bootstrapped $95 \%$ confidence interval ranged from 0.5958 to -0.0111 . Thus, the indirect effect was statistically significant, and there was mediation.

For the 14-hour, 300-passenger condition: The standardized regression coefficient between gender and affect was statistically significant, as was the relationship between affect and willingness to fly. The significance of this indirect effect was tested using bootstrapping procedures (Hayes, 2013) with 1,000 bootstrapped samples. The bootstrapped $95 \%$ confidence interval ranged from 0.6034 to 0.0298 . The indirect effect was not statistically significant, and there was no mediation in this condition.

\section{Discussion - Study 1}

The purpose of this study was to examine consumer attitudes towards CRIP. In the study, the researchers manipulated the length of flight and number of passengers. An additional independent variable was the gender of participants. First, the researchers hypothesized that consumers would be less willing to fly on 
short flights where the pilot could use CRIP. Second, it was hypothesized that the number of passengers on board would affect the willingness to fly. Third, it was predicted that there would be an effect of gender on the willingness to fly scores. Lastly, it was expected to see mediation of emotions on the relationship between the independent variable of gender and willingness to fly scores.

The first hypothesis was strongly supported by the data. In the 2-hour flights, participants were much less willing to fly with CRIP compared to the 14hour flights. This was expected because participants may believe that naps are not necessary on shorter flights. However, most consumers probably don't realize that pilots fly multiple short flights per day, and could be just as exhausted on a 2-hour flight, as they would be on a long-haul flight. Of note is the incident in February 2008 where both pilots of a Go! Airlines flight fell asleep on a short flight between two Hawaiian islands (NTSB, 2017).

The second hypothesis was supported by the data, although it should be noted that the effect size was small, and participants only appeared to be a concern to participants in the 2-hour flights. The researchers were a bit surprised by this data, as it was expected that participants would consider the safety of 300 passengers over 50 passengers, but it could be that they were more focused on the length of flight rather than the number of passengers.

The third hypothesis was a non-directional prediction, as there was not have enough prior literature to support a directional hypothesis. Hart and Rice (2016) did not find any gender effects in their data, and reported only country effects; that is, there were differences between participants from the United States and India, but not between males and females. On the other hand, Winter, Carryl, and Rice (2015) found that females were less willing to fly compared to their male counterparts when CRIP was used. It was surprising that the current study found such strong effects, and notes that females were much less willing to fly during CRIP compared to their male counterparts. This was the case in all four conditions, regardless of the length of flight or number of passengers. This does align with recent findings that females are less willing to ride in driverless ambulances (Winter, Rice, Keebler, \& Mehta, 2017), so it may be that females are less trusting in general of nontraditional situations that they are not familiar with. More research should examine this issue before coming to strong conclusions about the data.

Lastly, there appeared to be mediation of emotion on the relationship between the independent variable of gender and willingness to fly in all but the 14hour, 300-passenger condition. Specifically, the differences seen in the length of flight and gender were mediated by participants' emotional reaction to the different 
hypothetical scenarios. This aligns with Winter, Carryl, and Rice (2015), who also found that affect mediated the relationship between flying with and without CRIP and willingness to fly scores. The researchers discuss these issues in more detail in the General Discussion.

\section{Study 2 Introduction}

In Study 1, the researchers analyzed the perceptions of consumers about the use of CRIP in commercial flight. The findings showed that, in general, consumers were less willing to fly when CRIP was used in short flights compared to long flights. There was also a strong gender effect, whereby females were less willing to fly with CRIP compared to their male counterparts. The number of passengers on board did not appear to effect willingness to fly scores. The purpose of Study 2 was to determine if actual pilots who also rode in commercial airplanes shared consumer attitudes towards CRIP. It is noted that this study does not ask pilots how they feel about CRIP when they are piloting the aircraft, but instead asks about their attitudes towards CRIP when they are passengers. The study was delimited to only seeking commercial pilot responses. However, future research could expand on other aviation professionals who are knowledgeable about the effects of fatigue within the aviation industry. For study 2, it was hypothesized that the results from Study 1 would replicate to Study 2, but that pilots would be more willing to fly with CRIP compared to non-pilots. The hypotheses for study 2 were:

H1a: Willingness to fly ratings would be affected by the length of the flight; that is, shorter flights with CRIP would generate lower willingness to fly scores.

H2a: Willingness to fly ratings would be affected by the number of passengers; that is, a CRIP flight with more passengers would generate lower willingness to fly scores.

H3a: Willingness to fly scores would differ as a function of gender. This was a non-directional hypothesis.

H4a: Willingness to fly scores would differ as a function of whether the participant was a pilot or not; that is, we predicted that pilots would be more willing to fly with CRIP in general compared to non-pilots.

H5a: Affect would mediate the relationship between the IVs and willingness to fly. 


\section{Methods}

\section{Study 2}

Participants. There were 338 (162 females) non-pilot participants who took part in the study. The mean age was 38.07 years $(S D=12.04)$. All non-pilot participants were recruited from the United States via a convenience sample using Amazon's ${ }^{\circledR}$ Mechanical Turk ${ }^{\circledR}$ (MTurk). There were 160 (11 females) pilot participants who were recruited by posting a link on Curt Lewis' Flight Safety Information Newsletter (www.fsinfo.org) that goes out to 36,000 subscribers daily. The mean age was 48.77 years $(S D=10.74)$.

Materials, Procedure, and Design. Study 2 was identical to Study 1 with one exception. In this study, the researchers included pilots, solicited from Curt Lewis's Flight Safety Newsletter, as well as non-pilots, solicited via MTurk. Table 2 depicts the design along with average willingness to fly scores, standard deviations, and sample size.

\section{Results}

\section{Study 2}

To verify internal consistency, a Cronbach's Alpha test was completed for the affect data in this study and values ranged from .982 to .986, which implies high internal consistency. This allowed the data to be averaged into one affect score per participant. A Cronbach's Alpha was conducted on the willingness to fly data and revealed values ranging from .985 to .993 , thus indicating high internal consistency. Therefore, the scores were averaged into one willingness to fly score per participant.

Inferential Statistics. A mixed $2 \times 2 \times 2$ factorial ANOVA analysis was conducted on the data using length of flight and number of passengers as within participant factors and type of passenger as the between subjects factor. For the affect data, the main effect of length of flight was found to be significant, $F(1,495)$ $=179.29, p<0.001, \eta p^{2}=0.266$, and there was a significant main effect of number of passengers, $F(1,495)=29.06, p<0.001, \eta p^{2}=0.055$. There was also a significant main effect of type of passenger, $F(2,495)=25.20, p<0.001, \eta p^{2}=$ 0.092 . There was not a significant interaction between length of flight and type of passenger, $F(2,495)=0.64, p=0.640, \eta p^{2}=0.003$, between number of passengers and type of passenger, $F(2,495)=1.70, p=0.183, \eta p^{2}=0.007$, nor between length of flight, number of passengers, and type of passenger, $F(2,495)=1.17, p=0.311$, 
$\eta p^{2}=0.005$. There was a significant interaction between length of flight and number of passengers, $F(1,495)=8.32, p<0.01, \eta p^{2}=0.017$. Study results are depicted in Figure 3. For the willingness to fly data, the main effect of length of flight was found to be significant, $F(1,495)=149.97, p<0.001, \eta p^{2}=0.233$, as well as that of number of passengers, $F(1,495)=8.90, p<0.01, \eta p^{2}=0.018$, and type of passenger, $F(2,495)=26.64, p<0.001, \eta p^{2}=0.097$.

Table 2

A $2 \times 2 \times 3$ three-way mixed factorial design was used for Study 1 with the length of flight and number of passengers as within factors and gender as a between factor. Average willingness to fly scores, standard deviations and number of participants are depicted.

\begin{tabular}{lllll}
\hline Conditions & Type of Passenger & $\begin{array}{l}\text { Avg. Willingness to } \\
\text { Fly Score }\end{array}$ & $\begin{array}{l}\text { Standard } \\
\text { Deviation }\end{array}$ & N \\
\hline \multirow{4}{*}{ 2 hour, 50 Passengers } & Males & -0.00 & 1.14 & 176 \\
& Females & -0.73 & 1.14 & 162 \\
& Pilots & 0.24 & 1.35 & 160 \\
& Total & -0.16 & 1.27 & 498 \\
& Males & -0.07 & 1.20 & 176 \\
2 hour, 300 passengers & Females & -0.79 & 1.17 & 162 \\
& Pilots & 0.18 & 1.41 & 160 \\
& Total & -0.22 & 1.32 & 498 \\
& Males & 0.34 & 1.16 & 176 \\
14 hour, 50 passengers & Females & -0.18 & 1.22 & 162 \\
& Pilots & 0.68 & 1.33 & 160 \\
& Total & 0.28 & 1.28 & 498 \\
& Males & 0.36 & 1.21 & 176 \\
14 hour, 300 passengers & Females & -0.20 & 1.23 & 162 \\
& Pilots & 0.68 & 1.36 & 160 \\
& Total & 0.28 & 1.31 & 498 \\
\hline
\end{tabular}

There was also a significant interaction between length of flight and number of passengers, $F(1,495)=8.01, p<0.01, \eta p^{2}=0.016$. There was no significant interaction between length of flight and type of passenger, $F(2,495)=1.89, p=$ $0.152, \eta p^{2}=0.006$, number of passengers and type of passenger, $F(2,495)=0.229$, $p=0.795, \eta p^{2}=0.001$, nor length of flight, number of passengers, and type of passenger, $F(2,495)=0.38, p=0.684, \eta p^{2}=0.002$. Willingness to fly data are depicted in Figure 4. 
Mediation Analyses. For the 2-hour, 50-passenger condition: The standardized regression coefficient between male/pilot and affect was not statistically significant. The bootstrapped $95 \%$ confidence interval ranged from 0.0093 to 0.2245 . Thus, the indirect effect was not statistically significant, and there was not mediation.

For the 2-hour, 300-passenger condition: The standardized regression coefficient between male/pilot and affect was statistically significant, as was the relationship between affect and willingness to fly. The significance of this indirect effect was tested using bootstrapping procedures (Hayes, 2013) with 1,000 bootstrapped samples. The bootstrapped $95 \%$ confidence interval ranged from 0.0122 to 0.2646 . Thus, the indirect effect was statistically significant, and there was mediation.

For the 14-hour, 50-passenger condition: The standardized regression coefficient between male/pilot and affect was statistically significant, as was the relationship between affect and willingness to fly. The significance of this indirect effect was tested using bootstrapping procedures (Hayes, 2013) with 1,000 bootstrapped samples. The bootstrapped $95 \%$ confidence interval ranged from 0.0272 to 0.2720 . Thus, the indirect effect was statistically significant, and there was mediation.

For the 14-hour, 300-passenger condition: The standardized regression coefficient between male/pilot and affect was statistically significant, as was the relationship between affect and willingness to fly. The significance of this indirect effect was tested using bootstrapping procedures (Hayes, 2013) with 1,000 bootstrapped samples. The bootstrapped 95\% confidence interval ranged from 0.0466 to 0.2915 . Thus, the indirect effect was statistically significant, and there was mediation.

For the 2-hour, 50-passenger condition: The standardized regression coefficient between female/pilot and affect was statistically significant, as was the relationship between affect and willingness to fly. The significance of this indirect effect was tested using bootstrapping procedures (Hayes, 2013) with 1,000 bootstrapped samples. The bootstrapped 95\% confidence interval ranged from 0.5113 to 0.9669 . Thus, the indirect effect was statistically significant, and there was mediation.

For the 2-hour, 300-passenger condition: The standardized regression coefficient between female/pilot and affect was statistically significant, as was the relationship between affect and willingness to fly. The significance of this indirect 
effect was tested using bootstrapping procedures (Hayes, 2013) with 1,000 bootstrapped samples. The bootstrapped $95 \%$ confidence interval ranged from 0.5985 to 1.1143 . Thus, the indirect effect was statistically significant, and there was mediation.

For the 14-hour, 50-passenger condition: The standardized regression coefficient between female/pilot and affect was statistically significant, as was the relationship between affect and willingness to fly. The significance of this indirect effect was tested using bootstrapping procedures (Hayes, 2013) with 1,000 bootstrapped samples. The bootstrapped $95 \%$ confidence interval ranged from 0.5405 to 1.0412 . Thus, the indirect effect was statistically significant, and there was mediation.

For the 14-hour, 300-passenger condition: The standardized regression coefficient between female/pilot and affect was statistically significant, as was the relationship between affect and willingness to fly. The significance of this indirect effect was tested using bootstrapping procedures (Hayes, 2013) with 1,000 bootstrapped samples. The bootstrapped $95 \%$ confidence interval ranged from 0.5153 to 1.0249 . Thus, the indirect effect was statistically significant, and there was mediation.

\section{Discussion}

\section{Study 2}

The purpose of Study 2 was two-fold. First, the researchers wanted to replicate the findings from Study 1 to ensure that the effects discovered were not a Type 1 error, and second, the researchers wanted to examine the differences in attitudes towards CRIP between pilots and non-pilots. The hypotheses were similar to Study 1, with two exceptions. First, the researchers changed the non-directional hypothesis of gender to a directional one, and second, it was hypothesized that there would be a difference in willingness to fly scores as a function of whether the participant was a pilot or not.

The first hypothesis was strongly supported, as it was in Study 1. Willingness to fly scores were affected by the length of the flight, with participants much less willing to fly in CRIP conditions on the 2-hour flight compared to the 14-hour flight. Interestingly, this effect was pronounced with pilots as well as nonpilots. It was expected to see a stronger interaction in the data, whereby pilots would not show as much difference between the lengths of flight, but that was not the case. 
Pilots, as well as non-pilots, were not as willing to fly with CRIP on the shorter flights.

The second hypothesis was not supported very strongly by the data and replicated the findings from Study 1 . There were only minor differences between the 50 passenger and 300 passenger scenarios in some conditions. As with Study 1, it appeared that participants did not seem to care how many people were on board during CRIP. They only cared about the length of the flight.

The third hypothesis was again strongly supported by the data and replicated what was found in Study 1. The female participant group was, across the board, less willing to fly with CRIP compared to their male counterparts. It is noted that this finding also replicates the data of Winter, Carryl, and Rice (2015), who found similar gender effects. On the other hand, Hart and Rice (2016) did not find those effects, so further research should be conducted to see if this is a universal effect or study-specific.

The fourth hypothesis involved the difference in willingness to fly scores between pilots and non-pilots. As predicted, pilots were, across the board, more willing to fly with CRIP compared to non-pilots. The researchers want to note that most pilots are male, with only about $6 \%$ female pilots in the country. The sample was almost predominantly male, so the best comparison that can be made with this dataset is pilots to male consumers. In this case, pilots were more willing to fly with CRIP compared to male consumers.

Lastly, it was predicted that the main effects seen above would be mediated by emotions (affect). This was the case in most conditions, excluding the 2-hour, 50 passenger condition when comparing males and pilots. The researchers discuss this is more detail in the general discussion.

\section{General Discussion}

The overall purpose of this study was to examine perceptions of controlled rest in position (CRIP) during commercial airline flights. While some previous research has been conducted on consumer perceptions of CRIP (Hart \& Rice, 2016; Winter, Carryl \& Rice, 2015), to date, no known research has examined how these attitudes are affected by the length of the flight or the number of passengers on board. Furthermore, no study was found that has looked at the comparison between pilots and non-pilots on this issue. 
In both studies, the researchers manipulated the length of the flight, comparing a short 2-hour flight to a much longer 14-hour flight. It was hypothesized that participants would be less willing to fly in CRIP situations during short-haul flights, and the data firmly supports this prediction. In both studies, it was found that participants were less willing to fly if the pilots were napping on the shorter flight. While it was expected for non-pilots to be less willing to fly, because they often lack a thorough understanding of a pilot's daily flight schedule, it was somewhat surprising that this effect extended to pilots, as well. Presumably, pilots would know that a short flight does not equal a short workday. For example, the Go! Airlines flight (NTSB, 2017) showed that fatigue is caused by many more variables than just longer flights.

In both studies, the researchers also manipulated the number of passengers on board. While the findings were statistically significant, in both studies the effect size was small. This was a bit surprising, and it was thought that participants would consider a number of passengers to be a more important issue.

In both studies, the findings were analyzed as a function of Gender, and it was found that female participants were much less willing to fly during CRIP in all conditions, regardless of flight length or number of passengers. This supports previous research from Winter, Carryl, and Rice (2015), but conflicts with findings from Hart and Rice (2016), who did not find any gender effects. One reason for this might be that the current study had a larger sample size or perhaps the studies were conducted using different populations.

In the second study, the researchers added pilots to our participant pool, and it was found that they were more willing to fly during CRIP than both female and male non-pilots. It is noted that almost all the pilots who participated were male, and this is representative of the field, which only has $6 \%$ female pilots, and even less in commercial aviation. It was surprising, however, that the effects were not larger than they were. Some might expect pilots to strongly support CRIP, given that research has shown the benefits of CRIP, and it is already being used in some countries. However, the results were mixed. In the short flights, pilots were, in general, neutral about CRIP, and only somewhat supportive during the long flights. More research on pilots' perceptions of CRIP should be completed to learn more about their thoughts on this complicated topic.

In both studies, affect was examined as a mediator of the relationship between the independent variables and willingness to fly. In both studies, the data strongly supported the hypothesis that affect does mediate that relationship. In Studies 1 and 2, it mediated all but one condition in each study. There is prior 
literature suggesting that consumers are strongly motivated by their emotions and tend to make decisions based on emotions rather than cognitive processes (Rice, Winter, \& Tokarski, 2015; Winter \& Rice, 2015; Winter, Rice, Tamilselvan, \& Tokarski, 2016). This study expands on those findings and further adds to the theoretical predictions that affect is a strong mediator and one that should not be ignored in aviation science.

\section{Theoretical Findings}

The findings from these two studies expand on the sparse literature regarding CRIP. In previous studies, it was found that attitudes towards CRIP are affected by different variables, including Gender and the participants' country of origin. The current findings replicated the gender effect, and add the length of flight and number of passengers as additional variables to consider. Further research should be conducted to ensure that the findings replicate and that other potential variables are considered.

The findings also contribute to the theoretical foundations of affect. Research has thoroughly addressed the topic of affect, and several recent papers discuss how affect mediates various relationships in aviation. Winter, Rice, Tamilselvan, and Tokarski (2016) published a study demonstrating affect as a mediator between the use of an unmanned aerial vehicle on two missions and participants' perceived threat towards privacy. Rice, Winter, and Tokarski (2015) discovered that affect mediated the relationship between consumer's trust in pilots based on perceived sociability factors. Lastly, Winter and Rice (2015) conducted a study that demonstrated mediation of affect on the hypothetical behavior of pilots and consumer's perception of their likelihood to have a mental illness.

\section{Practical Applications}

This study provides research that has been missing from the body of literature on the use of controlled rest in position within aviation. The industry is mixed in its acceptance of this countermeasure toward fatigue. Scientific studies (Caldwell, 2005; Rosekind et al., 1995) have suggested advantages toward the use of short naps in aviation, yet only a few countries have adopted and implemented procedures for the use of CRIP. The current study has presented CRIP from a consumer's perspective and found differences in willingness to fly based on factors such as length of the flight, the number of passengers, gender, and whether or not an individual was a pilot. In general, consumers were less willing to fly with CRIP on shorter flights than longer ones while pilots were more willing to fly than consumers. 
Affect was also shown to be a mediating variable in the majority of conditions. Within the limitations of this sample, the results of this study suggest that the reaction of participants was highly influenced by their emotions. This response encourages the infusion of knowledge on the topic of CRIP so consumers may make their decisions based on more cognitive information and not with emotional responses. If the industry decides to allow the use of CRIP in the United States, the findings of this study indicate that consumers need to be informed of CRIP advantages, and the role CRIP would have in decreasing the effects of fatigue, while striving to increase the overall safety of flight operations.

\section{Limitations}

There are several limitations in this study. First, the data was collected via a convenience sample online and via email. This has implications for external validity, and one should be cautious about generalizing the findings beyond that target population. There may be certain types of individuals that subscribe to complete online human intelligence tasks, and this population has to be online and decide to voluntarily complete studies. Further research should examine different target populations and samples, ages, socioeconomic factors, etc., and caution should be used when making generalizations of the findings. Second, there were age differences between the pilots $(M=48.77, S D=10.74)$ and non-pilots $(\mathrm{M}=$ $38.07, S D=12.04$ ) in Study 2, which could help to explain some of the differences between those groups. Age-related research often shows cognitive differences as a function of different generations, and these differences could manifest in this population, as well. Further research should attempt to sample older non-pilots, as well as younger pilots.

\section{Conclusions}

CRIP is an important topic that needs to be discussed in more detail before it is widely used in aviation. Currently, only a few countries allow CRIP. The purpose of this paper was to examine both pilot and non-pilot perceptions towards CRIP in the United States. In both studies, the researchers manipulated the length of the flight and number of passengers on board during hypothetical scenarios. There were also examined comparisons between female and male non-pilots and pilots. The data concluded that length of the flight is an important factor in willingness to fly with CRIP, while a number of passengers only played a weak role in willingness to fly. Gender, on the other hand, is a significant factor, with female participants being less willing to fly with CRIP than their male counterparts. Pilots were the most willing to fly with CRIP; however, they were not as supportive 
International Journal of Aviation, Aeronautics, and Aerospace, Vol. 4 [2017], Iss. 3, Art. 6

of CRIP as might have been expected. Lastly, it was found that affect mostly mediated the relationships between the independent variables and willingness to fly with CRIP. Further research should examine these effects with additional variables and situations. 


\section{References}

Adams, D. A., Nelson, R. R., \& Todd, P. A. (1992). Perceived usefulness, ease of use, and usage of information technology: A replication. MIS Quarterly, 16(2), 227-247.

Air Line Pilots Association, International (ALPA). (2013). Guide to Part 117 flight time limitations and rest requirements. Air Line Pilots Association, International, Washington, D.C. Retrieved from: http://www3.alpa.org/portals/alpa/committees/ftdt/Part-117-Flight-TimeLimitations-and-Rest-Requirements.pdf

Bodenhausen, G. V. (1993). Emotions, arousal, and stereotypic judgments: A heuristic model of affect and stereotyping. In D .M. Mackie \& D. L. Hamilton (Eds.), Affect, cognition, and stereotyping: Interactive processes in group perception (pp. 13-37). San Diego, CA: Academic Press.

Bower, G. H. (1991). Mood congruity of social judgment. In J. Forgas (Ed.), Emotion and social judgment (pp. 31-54). Oxford, UK: Pergamon.

Caldwell, J. A. (2005). Fatigue in aviation. Travel Medicine and Infectious Disease, 3(2), 85-96. doi:http://dx.doi.org/10.1016/j.tmaid.2004.07.008

Clore, G. L., Schwarz, N., \& Conway, M. (1994). Cognitive causes and consequences of emotion. In R. S. Wyer, Jr. \& T. K. Srull (Eds.), Handbook of social cognition (2nd ed., pp. 323-417). Hillsdale, NJ: Erlbaum.

Davis, F. D. (1989). Perceived Usefulness, Perceived Ease of Use, and User Acceptance of Information Technology. MIS Quarterly, 13(3), 319-340.

Dholakia, U. M. (2001). A motivational process model of product involvement and consumer risk perception. European Journal of Marketing, 35(11), 1340-1360.

Dorrian, J., Rogers, N. L., \& Dinges, D. F. (2005). Psychomotor vigilance performance: Neurocognitive assay sensitive to sleep loss (Doctoral dissertation, Marcel Dekker).

Driskell, J. E., \& Mullen, B. (2005). The efficacy of naps as a fatigue countermeasure: a meta-analytic integration. Human Factors, 47(2), 360377. 
Ferrara, M., \& De Gennaro, L. (2000). The sleep inertia phenomenon during the sleep-wake transition: theoretical and operational issues. Aviation, space, and environmental medicine, 71(8), 843-848.

Forgas, J. P. (1995). Mood and judgment: The affect infusion model (AIM). Psychological Bulletin, 117, 39-66.

Frijda, N. H. (1986). The emotions. Cambridge, UK: Cambridge University Press. Bulletin, 117, 39-66.

Goode, J. H. (2003). Are pilots at risk of accidents due to fatigue? Journal of safety research, 34(3), 309-313.

Hart, M., \& Rice, S. (2016). Consumer Perception of Controlled Rest in Position. Proceedings of the 2016 Human Factors and Psychology Student Conference.

Hartzler, B. M. (2013). Fatigue on the flight deck: The consequences of sleep loss and the benefits of napping. Accident Analysis and Prevention, 62, 309318. doi:http://dx.doi.org/10.1016/j.aap.2013.10.010

Hayes, A. F. (2013). Introduction to mediation, moderation, and conditional process analysis: A regression-based approach. New York: Guilford Press.

Lazarus, R. S. (1991). Progress on a cognitive-motivational-relational theory of emotion. American psychologist, 46(8), 819-834.

Levenson, R. (1994). Human emotion: a functional view. In P. Ekman \& R. J. Davidson (Eds.), The nature of emotion (pp. 123-126). New York: Oxford University Press.

Loewenstein, G. (1996). Out of control: Visceral influences on behavior. Organizational Behavior and Human Decision Processes, 65, 272-292.

NASA. (1994). Crew Factors in Flight Operations IX: Effects of Planned Cockpit Rest on Crew Performance and Alertness in Long-Haul Operations. (NASA Technical Memorandum 108839). Moffett Field, California: Ames Research Center. 
NTSB. (2017). Report SEA08IA080 on go! Airlines flight 1002. Retrieved from: https://www.ntsb.gov/_layouts/ntsb.aviation/brief.aspx?ev_id=20080222X 00229\&key=1

Oatley, K., \& Johnson-Laird, P.N. (1996). The communicative theory of emotions: Empirical tests, mental models, and implications for social interaction. In L.L. Martin \& A. Tesser (Eds.), Striving and feeling: Interactions among goals, affect, and self-regulation. Hillsdale, NJ: Erlbaum.

Pramatari, K., \& Theotokis, A. (2009). Consumer acceptance of RFID-enabled services: A model of multiple attitudes, system characteristics and individual traits. Rochester: Social Science Research Network. doi:http://dx.doi.org/10.2139/ssrn.1329907

Powell, D., Spencer, M. B., Holland, D., Broadbent, E., \& Petrie, K. J. (2007). Pilot fatigue in short-haul operations: Effects of number of sectors, duty length, and time of day. Aviation, Space, and Environmental Medicine, 78(7), 698-701.

Purnell, M. T., Feyer, A. M., \& Herbison, G. P. (2002). The impact of a nap opportunity during the night shift on the performance and alertness of 12-h shift workers. Journal of sleep Research, 11(3), 219-227.

Rice, S., Mehta, R., Dunbar, V., Oyman, K., Ghosal, S., Oni, M.D. \& Oni, M.A. (2015, January). A valid and reliable scale for consumer willingness to fly. Proceedings of the 2015 Aviation, Aeronautics, and Aerospace International Research Conference, Phoenix, AZ.

Rice, S. \& Winter. S. (2015, June). A quick affect scale: Providing evidence for validity and reliability. Proceedings from the 10th International Conference on Interdisciplinary Social Sciences, Split, Croatia.

Rice, S., Winter, S. R., \& Tokarski, R. (2015). How Trust in Commercial Airline Pilots is Affected by Their Perceived Sociability: A Mediation Analysis. Collegiate Aviation Review, 33(2), 1.

Rice, S., \& Winter, S. R. (2015). Which Passenger Emotions Mediate the Relationship Between Type of Pilot Configuration and Willingness to Fly in Commercial Aviation?. Aviation Psychology and Applied Human Factors. 
Roach, G. D., Darwent, D., Sletten, T. L., \& Dawson, D. (2011). Long-haul pilots use in-flight napping as a countermeasure to fatigue. Applied ergonomics, 42(2), 214-218.

Rosekind, M. R., Smith, R. M., Miller, D. L., Co, E. L., Gregory, K. B., Webbon, L. L., ... \& Lebacqz, J. V. (1995). Alertness management: strategic naps in operational settings. Journal of Sleep Research, 4(s2), 62-66.

Schwarz, N. \& Clore, G.L. (1983). Mood, misattribution and judgments of wellbeing: Informative and directive functions of affective states. Journal of Personality and Social Psychology, 45, 513- 523.

Schwarz, N. \& Clore, G. (1988). How do I feel about it? The information function of affective states. In K. Fiedler \& J.P. Forgas (Eds.), Affect, cognition, and social behavior: New evidence and integrative attempts (pp. 44-63). Toronto: C.J. Hogrefe.

Schwarz, N. (1990). Feelings as information: Informational and motivational functions of affective states. In E. T. Higgins \& R. M. Sorrentino (Eds.), Handbook of motivation and cognition: Foundation s of social behavior (Vol. 2, pp. 527-561). New York: Guilford Press.

Schwarz, N., \& Clore, G. (1996). Feelings and phenomenal experiences. In E. T. Higgins \& A.W. Kruglanski (Eds.), Social psychology: Handbook of basic principles (pp. 433-465). New York: Guilford Press.

Simon, H. A. (1967). Motivational and emotional controls of cognition. Psychological Review, 74, 29-39.

Thefreedictionary (2014). Willingness. Retrieved from: http://www.thefreedictionary.com/willingness

Trafimow, D., \& Sheeran, P. (1998). Some tests of the distinction between cognitive and affective beliefs. Journal of Experimental Social Psychology, 34, 378-397.

Trafimow, D., \& Sheeran, P. (2004). A theory about the translation of cognition into affect and behavior. In G. Maio \& G. Haddock (Eds.), Contemporary perspectives in the psychology of attitudes: The Cardiff Symposium (pp. 57-76). London: Psychology Press. 
Trafimow, D., Sheeran, P., Lombardo, B., Finlay, K. A., Brown, J., \& Armitage, C.J. (2004). Affective and cognitive control of persons and behaviors. British Journal of Social Psychology, 43, 207-224.

Transportation Safety Board of Canada (TSB). (2011). Accident Investigation Report A11F0012: Pitch Excursion, Air Canada, Boeing 767-333, C-

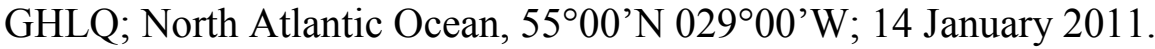

Tooby, J., \& Cosmides, L. (1990). The past explains the present: Emotional adaptations and the structure of ancestral environments. Ethology and Sociobiology, 11, 375424.

Werfelman, L., Rash, C. E., \& Manning, S. D. (2009). Rest in place. Aerosafety World. Flight Safety Foundation, Washington, D. C.

Winter, S. R., Rice, S., Keebler, J. R., \& Mehta, R. (2017, March). Patient perceptions on the use of an auto-piloted emergency medical transport: An affective perspective. 2017 International Symposium on Human Factors and Ergonomics in Health Care, New Orleans, Louisiana.

Winter, S. R., Carryl, J., \& Rice, S. (2015). Controlled rest in position (CRIP): Consumer perceptions in the United States. Collegiate Aviation Review, $33(1), 14-28$.

Winter, S. R. \& Rice, S. (2015). Pilots Who Are Perceived as Unsociable Are Perceived as More Likely to Have a Mental Illness. Aviation Psychology and Applied Human Factors.

Winter, S. R., Rice, S., Tamilselvan, G., \& Tokarski, R. (2016). Mission-based citizen views on UAV usage and privacy: an affective perspective. Journal of Unmanned Vehicle Systems, 4(2), 125-135.

Winter, S. R., Rice, S., Rains, T., Milner, M., \& Mehta, R. (2017). A longitudinal study on the alteration of consumer perceptions and the use of pilot medication. Journal of Air Transport Management, 59, 100-106.

Zajonc, R. (1998). Emotions. In D. Gilbert, S. Fiske, \& G. Lindzey (Eds.), The handbook of social psychology (Vol. 1, pp. 591-632). New York: Oxford University Press. 
International Journal of Aviation, Aeronautics, and Aerospace, Vol. 4 [2017], Iss. 3, Art. 6

Zhao, J., \& Kling, C. L. (2004). Willingness to pay, Compensating variation, and the cost of commitment. Economic Inquiry, 42(3), 503-517. Retrieved from: http://search.proquest.com/docview/200862760?accountid=27313 


\section{Appendices}

\section{Appendix A}

Affect Scale (Rice \& Winter, 2015)

Please respond how strongly you agree or disagree with the following statements:

1. I feel good about this.

Strongly Disagree Disagree Neutral Agree Strongly

Agree

2. I feel positive about this.

Strongly Disagree Disagree Neutral Agree Strongly

Agree

3. I feel favorable about this.

Strongly Disagree Disagree Neutral Agree Strongly

Agree

4. I feel cheerful about this.

Strongly Disagree Disagree Neutral Agree Strongly

Agree

5. I feel happy about this.

Strongly Disagree Disagree Neutral Agree Strongly

Agree

6. I feel enthusiastic about this.

Strongly Disagree Disagree Neutral Agree Strongly

Agree

7. I feel delighted about this.

Strongly Disagree Disagree Neutral Agree Strongly

Agree 


\section{Appendix B}

Consumer Willingness to Fly Scale (Rice et al., 2015).

Please respond how strongly you agree or disagree with the following statements.

1. I would be willing to fly in this situation.

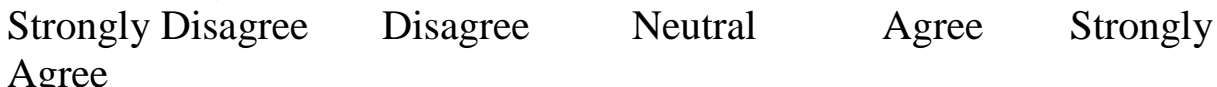

2. I would be comfortable flying in this situation.

Strongly Disagree Disagree Neutral Agree Strongly

Agree

3. I would have no problem flying in this situation.

Strongly Disagree Disagree Neutral Agree Strongly

Agree

4. I would be happy to fly in this situation.

Strongly Disagree Disagree Neutral Agree Strongly

Agree

5. I would feel safe flying in this situation.

Strongly Disagree Disagree Neutral Agree Strongly

Agree

6. I have no fear of flying in this situation.

Strongly Disagree Disagree Neutral Agree Strongly

Agree

7. I feel confident flying in this situation.

Strongly Disagree Disagree Neutral Agree Strongly

Agree 


\section{Appendix C}

Figures

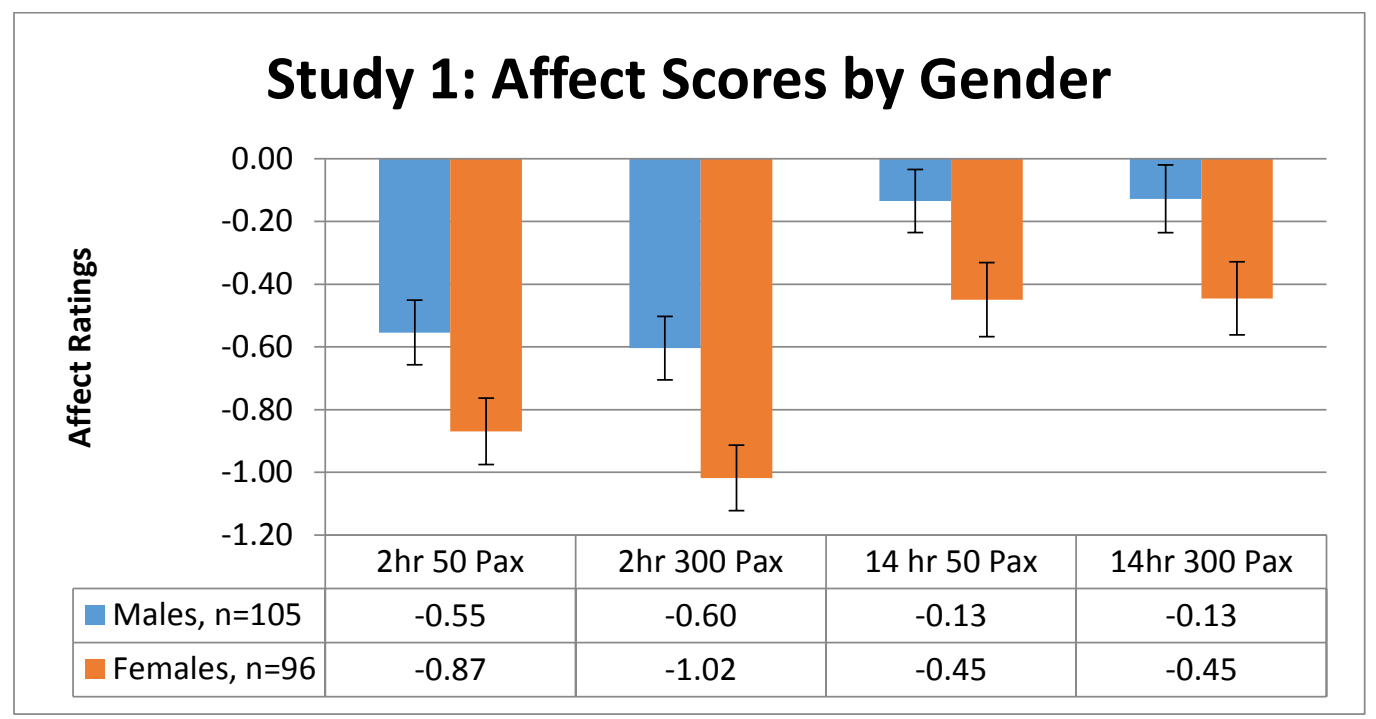

Figure 1. Average affect scores by gender for Study 1. Standard error bars included. 


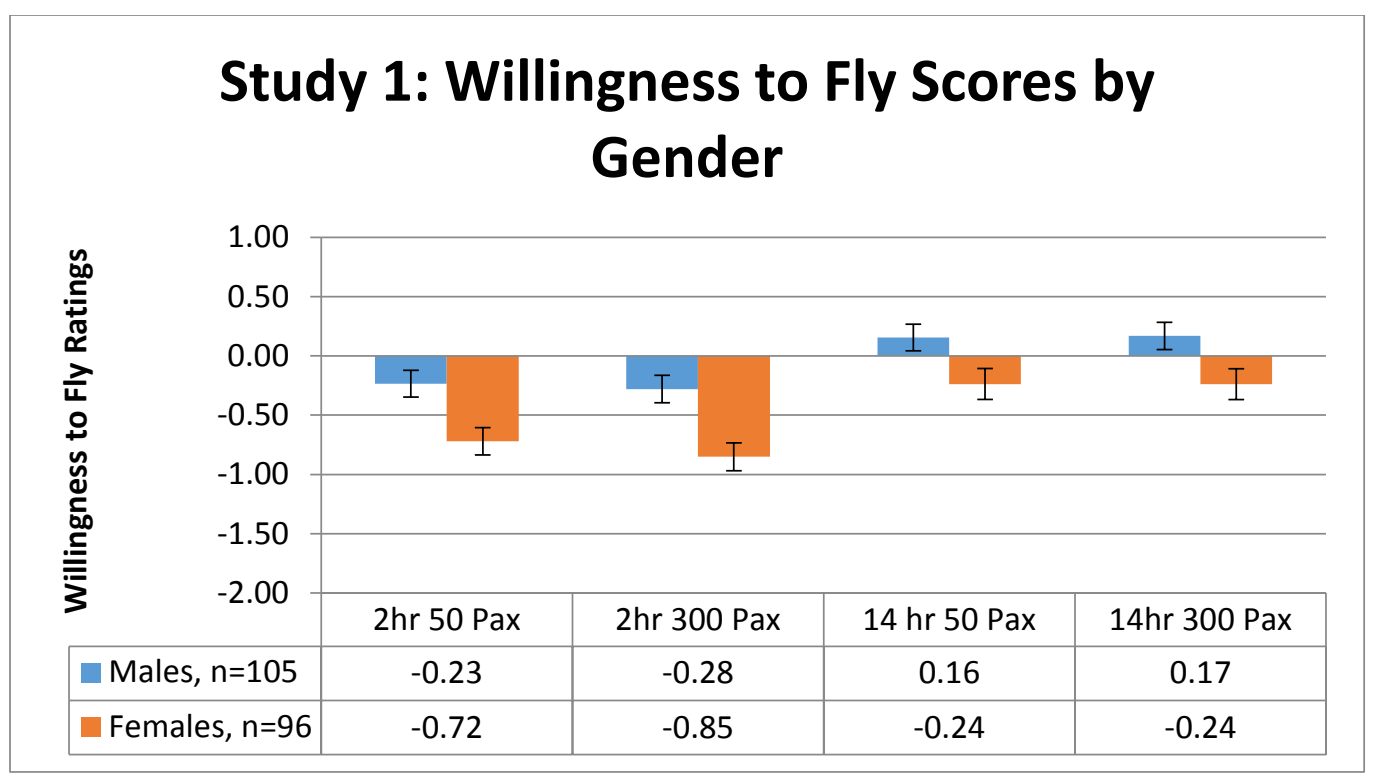

Figure 2. Study 1 average willingness to fly scores by gender. Standard error bars included.

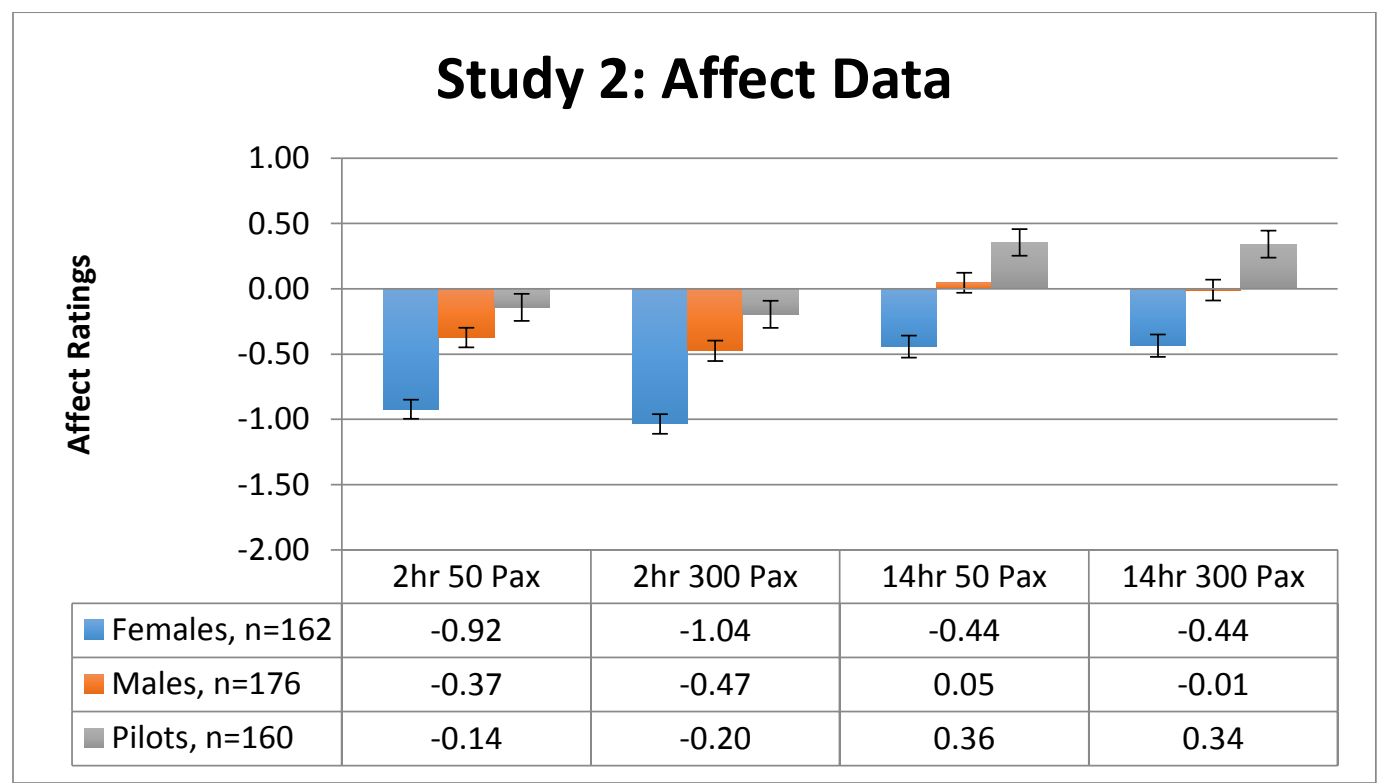

Figure 3. Study 2 average affect scores. Standard error bars included. 


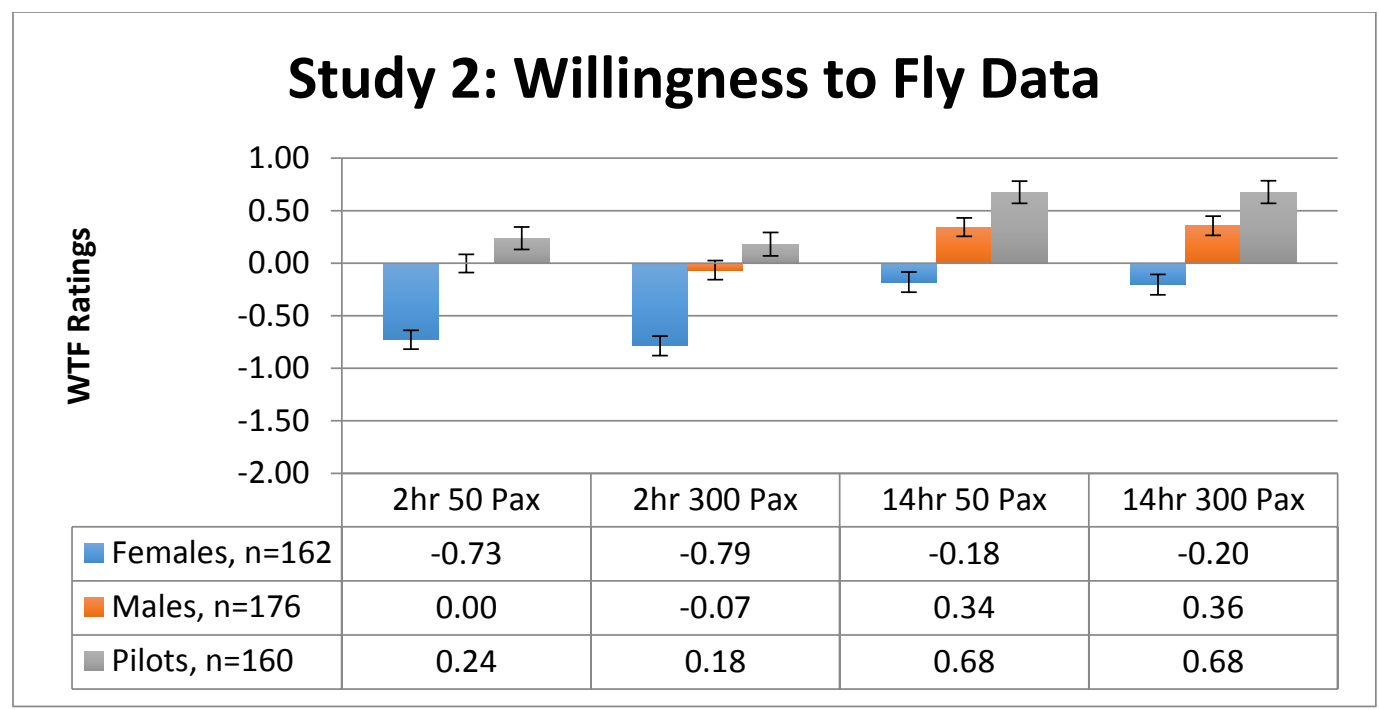

Figure 4. Study 2 average willingness to fly data. Standard error bars included. 